\title{
On the nature of tense in finite control ${ }^{1}$
}

\author{
Sobre a natureza do tempo em controle finito \\ Daniela Isac \\ Ivanna Richardson \\ Concordia University CMLL (Linguistics Program)
}

\begin{abstract}
This paper focuses on finite control in Persian, a language in which the embedded verb of control contexts occurs in a finite mood, more specifically in the subjunctive. Finite control poses significant challenges to classical theories of obligatory control, which exclude PRO from finite environments. Together with Landau 2013, we propose that finite control can in fact occur, under certain conditions. We show that the ambivalent nature of $\mathrm{T}$ in these contexts can be accounted for in a feature system which uses an interpretable/uninterpretable distinction, as well as a valued/unvalued distinction, and in which valuation and interpretability are independent from each other (Pesetsky and Torrego 2007). We propose that there are two mechanisms by which $\mathrm{T}$ can obtain an interpretation at LF: one is feature valuation, a process that depends on Agree and that takes place in the syntactic component, and the other one is index sharing - assigning [T] the same index as other instances of this feature with which [T] establishes a permanent link via feature checking. Apart from being able to account for the apparent conflicting behaviour of $\mathrm{T}$ in finite control clauses in Persian, such a system has two added benefits; (i) it allows us to derive the referential index of PRO - the null subject of finite control clauses in Persian, and (ii) it allows us to account for a surprising property of finite control clauses in Persian, namely the unavailability of overt subjects.
\end{abstract}

Keywords: Finite control; T, LF, subjunctive finite mood

Resumo: Este trabalho aborda o controle finito em persa, uma língua em que o verbo encaixado de contextos de controle ocorre em modo finito, mais especificamente no subjuntivo. O controle finito apresenta desafios significativos para teorias clássicas de controle obrigatório, que excluem PRO de ambientes finitos. Seguindo Landau 2013, propomos que o controle finito possa ocorrer, sob certas condições. Mostramos que a natureza ambivalente de T nesses contextos pode ser explicada em um sistema de traços que utiliza uma distinção interpretável/ não-interpretável, bem como uma distinção valorizado/não-valorizado, em que a valorização e a interpretabilidade são independentes entre si (Pesetsky e Torrego 2007). Propomos que haja dois mecanismos pelos quais T pode obter uma interpretação na FL: um é através de valorização de traços, um processo que depende de Concordância e que ocorre no componente sintático, e o outro é através de compartilhamento de índices - atribuir a [T] o mesmo índice que outras instâncias desse traço com o qual [T] estabelece um vínculo permanente através de checagem de traços. Além de poder dar conta do comportamento aparentemente conflitante de $\mathrm{T}$ em orações de controle finito em persa, tal sistema ainda possui dois benefícios adicionais: (i) permite a derivação do índice referencial de $\mathrm{PRO}$ - o sujeito nulo de orações de controle finito em persa, e (ii) permite dar conta da propriedade surpreendente de orações de controle finito em persa, a saber, a não-disponibilidade de sujeitos plenos.

Palavras-chave: Controle finito; Forma lógica, T, modo finito, subjuntivo

\footnotetext{
${ }^{1}$ This work was supported by funding from the Fonds Québecois de recherche sur la société et la culture for the project Interfaces Dynamiques. Volet 3.
} (Grant no. SE-137253, P.I. Anne-Marie Di Sciullo). 


\section{Aim of the paper}

This general goal of this paper is to contribute to the syntactic and semantic analysis of obligatory control in finite complements (henceforth finite control).

(1) [MatrixClause Subject $_{i}$ V-of-control

[EmbeddedClause $\left[\mathrm{PRO}_{\mathrm{i}}\left[v P\right.\right.$... $\left.\left.\left.\left.\mathrm{V}_{\text {Finite }}\right]\right]\right]\right]$

Finite control poses significant challenges to classical theories of obligatory control, which exclude PRO from finite environments. Landau 2013 proposes that finite control can in fact occur, but it is subject to certain restrictions. In particular, in Landau's view, finite control can occur in all finite complement clauses, except for those in which are both $[+\mathrm{T}]$ and $[+\mathrm{Agr}]$. In other words, according to this generalization, finite obligatory control occurs if the embedded finite clause is (i) [-T], [+Agr]; (ii) [+T], [-Agr]; or (iii) [-T], [-Agr]. This paper focuses on finite control in Persian, a language in which the embedded verb of finite control contexts occurs in the subjunctive.

\section{(2) zian $_{i}$ mi-tun-e $\quad\left[P R O_{i}\right.$ be-r-e] \\ $\mathrm{Jian}_{\mathrm{i}}$ DUR-be.able-3SG [PRO $\mathrm{PRUBJN}_{\mathrm{i}}$-go-3SG] \\ 'Jian is able to go.'}

Given that the subjunctive verb is overtly inflected for person and number, it is reasonable to assume that subjunctive clauses are [+Agr]. On the other hand, if Landau's 2013 generalization is on the right track, then subjunctive control clauses in Persian must be [-T]. However, the evidence suggests that Persian subjunctive control clauses are both $[+\mathrm{T}]$ and [-T]. This raises questions about what the features $[+\mathrm{T}]$ and $[-\mathrm{T}]$ actually mean. We propose that the apparent conflict between the two values of the $\mathrm{T}$ feature $([+\mathrm{T}]$ and $[-\mathrm{T}])$ can be resolved if we abandon the binary feature system used by Landau and we replace it with a system which uses an interpretable/uninterpretable distinction, as well as a valued/unvalued distinction, and in which valuation and interpretability are independent from each other (as in Pesetsky and Torrego 2007). Apart from being able to account for the apparent conflicting behaviour of $\mathrm{T}$ in finite control clauses in Persian, such a system has two added benefits; (i) it will allow us to derive the referential index of PRO - the null subject of finite control clauses in Persian, and (ii) it will allow us to account for a surprising property of finite control clauses in Persian, namely the unavailability of overt subjects.

\section{Finite control in Persian}

Complement clauses embedded under obligatory control verbs in Persian can occur in the subjunctive, as illustrated in (3).

(3)

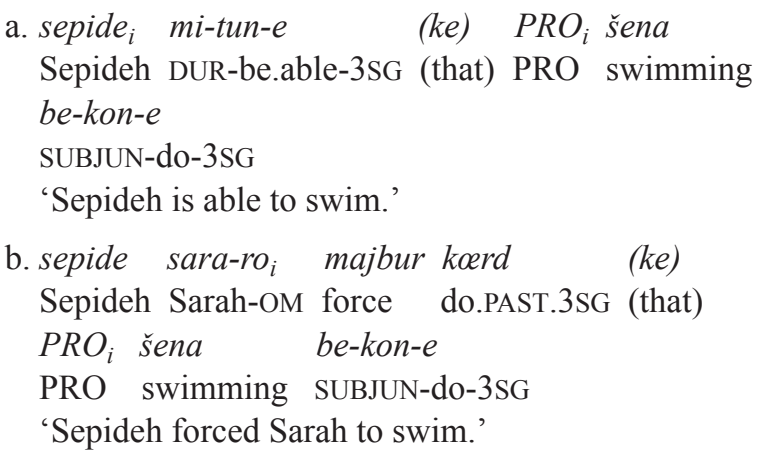

Given that classical theories of obligatory control exclude PRO from finite environments, one legitimate question is whether the empty subject of the embedded clause is indeed PRO. According to Landau 2013 there are two criterial properties that PRO has: PRO must be coindexed with a matrix NP, and PRO must get a bound variable reading.

(4) The Obligatory Control (OC) Signature. (Landau 2013) In a control construction $\left[\ldots . \mathrm{X}_{\mathrm{i}} \ldots . . \mathrm{S}_{\mathrm{S}} \mathrm{PRO}_{\mathrm{i}} \ldots . . . . ..\right]$, where $\mathrm{X}$ controls the PRO subject of the clause $\mathrm{S}$ :

(a) The controller(s) X must be (a) codependent(s) of $\mathrm{S}$.

(b) PRO (or part of it) must be interpreted as a bound variable.

We can thus check whether Persian finite control contexts bear the OC signature and thus whether the empty subject of the embedded clause is indeed a PRO.

In (3.a) the empty subject of the embedded clause is coindexed with sepide - the subject of the main clause, whereas in (3.b) the empty embedded subject is coindexed with the matrix object sara. Both of these controllers are codependents of the subjunctive clause, as predicted by condition (a) in (4) since both the controllers and the subjunctive clause are arguments of the same (matrix) verbal predicate. Moreover, the empty subject of the finite control clauses in Persian also satisfies the second condition in (4). This can be illustrated in the following context. Suppose that Sepideh, Sarah, and Ashkan promised to teach a class for Mary while Mary is away at a conference. This is compatible with the following two scenarios: 
(5) - scenario 1:

they each promised to teach a class - Sepideh promised that he (Sepideh) will teach a class, Sarah promised that she (Sarah) will teach a class, and Askan promised that he (Askan) will teach a class.

- scenario 2:

the three of them promised they will teach a class and they decided it will be Ashkan

Now consider the following sentence:

(6) (a) Fahrt Ashkan yad-e $\int=$ raeft

Only Ashkan memory-3SG.CL=go.PAST.3.SG

[PRO dars be-de]

[PRO class SUBJUN-give]

'Only Ashkan forgot to teach a class.'

This sentence is true only under scenario 1 . In other words the only interpretation of (6) is Ashkan $=$ only $\mathrm{x}[\mathrm{x}$ forgot $x$ to teach], in which PRO receives a bound variable reading. Crucially the strict reading for PRO (Ashkan = only $\mathrm{x}$ [x forgot Ashkan to teach]), which would obtain under scenario 2 , is not available. We will thus conclude, together with Hashemipour 1988, Ghomeshi 2001, Darzi 2008, Karimi 2008, and Richardson 2016 that the empty subject of the subjunctive clauses embedded under obligatory control verbs in Persian is indeed PRO.

\section{The [T] feature in Persian finite control clauses}

Landau 2004, 2013 proposes that finite control configurations are restricted to particular feature combinations on the embedded clause. More specifically, obligatory control occurs only in cases in which at least one of the features $[\mathrm{T}]$ or $[\mathrm{Agr}]$ is defective.

(7) The finiteness rule for Obligatory Control. (Landau 2013, ex. (178), p. 90)

In a fully specified complement clause (i.e. the $\mathrm{I}^{0}$ head carries slots for both $[\mathrm{T}]$ and $[\mathrm{Agr}])$;

a. If $\mathrm{I}^{0}$ carries both semantic tense and agreement $([+\mathrm{T}]$, $[+\mathrm{Agr}])$, no Control obtains.

b. Elsewhere, Obligatory Control obtains.

Notice that according to this generalization finite control is an elsewhere case. In other words, finite control occurs anywhere except in finite clauses which are [+T], [+Agr]. In positive terms, what the finiteness rule says is that obligatory control occurs in finite clauses that are (i) [-T], [+Agr]; (ii) [+T], [-Agr]; or (iii) [-T], [-Agr].
When examining Persian finite control clauses for these two features, it is clear that Persian subjunctive clauses are $[+\mathrm{Agr}]$, because the subjunctive verb is overtly inflected for person and number. (8) shows how the morphological form of the subjunctive verb varies with person (1st person vs 3rd person).

(8) a. (mcen) mi-tun-cem [(ke) PRO be-r-cem].

(I) DUR-be.able-1SG [(COMP) PRO SUBJUN-go-1SG] 'I am able to go'
b. Zian mi-tun-e [(ke) PRO bi-ad] jian DUR-be.able-3SG [(COMP) PRO SUBJUN.go.3SG] 'Jian is able to go.'

With respect to the [T] feature, if Landau's generalization about finite control is on the right track, Persian subjunctive control clauses must be [-T], because $[+\mathrm{T}]$ would correlate with no control cases, and we have shown above in section 2 that contexts like (3) are genuine obligatory control configurations. However, the evidence suggests that subjunctive control clauses in Persian are both $[+\mathrm{T}]$ and $[-\mathrm{T}]$. Such evidence is presented below.

\subsection{Persian subjunctive control clauses are $[-T]$}

Gomeshi 2001 argues that subjunctive embedded clauses lack temporal independence given that the embedded clause and the matrix clause cannot license temporal modifiers that are independent of each other, as illustrated in (9). This contrasts with (10), which shows that such disjoint temporal adverbs in the matrix clause and the embedded clause are possible in non-control environments.

(9) Control

*bizandiruz mi-tunest (ke) faerda

Bijan yesterday DUR-can.PAST.3SG (that) tomorrow

be-r-e

SUBJUN-go-3SG

'*Bijan could yesterday go tomorrow.' (Ghomeshi 2001:26, (39a))

(10) Non-control
*bizcen diruz
goft
(ke) farda
Bijan yesterday say.PAST.3SG (that) tomorrow
$m i-r-e$
DUR-go-3SG
'Bijan said yesterday he'd go tomorrow.' (Ghomeshi
2001:26, (39f)) 
This conclusion was challenged by Darzi $2008^{2}$, who provides an apparent counterexample to Ghomeshi's 2001 claim.

(11) sara diruz $\quad$ toesmim $=$ gereft $\quad(k e)$

Sara yesterday decision.take.PAST.3SG (that)

faerda be-r-e

tomorrow SUBJUN-go-3SG

'Sara decided yesterday to go tomorrow.' (Taleghani

2006:114, (51b))

In (11), the main clause licenses a past tense temporal modifier, whereas the embedded clause contains a future temporal modifier. As such, (11) is problematic for Gomeshi's claim that subjunctive clauses embedded under control verbs lack temporal independence. However, the matrix verb in (11) does not display the properties of genuine control verbs. In particular, the verb toesmim=gereftcen 'to decide' allows the agreement on the embedded verb to be different from the agreement on the matrix verb, as shown in (12).

\section{(12) Ptcesmim=gereft-cem (ke) bi-ad. (Gomeshi 2001, ex. (13.d)) \\ decision=get.PAST-1SG (COMP) SUBJUN-come.3SG \\ '*I decided him to come.'}

This is in violation of the first condition of the OC signature in (4), which says that in a genuine obligatory control configuration the controller must be a codependent of the embedded clause that contains PRO. Clearly, in (12), the empty subject of the embedded clause is not controlled by any argument in the matrix clause, and this violates the codependence condition. This in turn casts doubt on whether the verb that occurs in (11) is a genuine obligatory control verb in Persian. We will thus assume that (11) is only an apparent counterexample to the lack of temporal independence of subjunctive control clauses in Persian and that the lack of independent temporal reference of these clauses is genuine. This supports Persian the conclusion that subjunctive control clauses in Persian are [-T].

\subsection{Subjunctive control clauses are $[+T]$}

There is also evidence that Persian subjunctive control clauses are $[+\mathrm{T}]$. Such evidence is related to the fact that temporal adverbs can in fact be licensed in finite control clauses, as long as these adverbs are not disjoint

\footnotetext{
$\overline{2}$ Darzi 2008 follows Taleghani 2006 in providing the counterexample in (11).
}

from the temporal reference of the matrix clause. This is illustrated in (13) and (14).

(13) Puna mi-tun-aen (ke) Pun-movqe be Pin they DUR-can-3PL (that) then to this resturan be-r-cen restaurant SUBJUN-go-3PL 'They can/are able to go to this restaurant then. (Ilkhanipour, 2014, ex (8))

(14) to haeq=dar-i $\quad$ (ke) faerda nahar you right=have-2SG (that) tomorrow lunch bo-xor- $i$ SUBJUN-eat-2SG 'You have the right to have lunch tomorrow.' (Ilkhanipour, 2014, ex (9))

Notice that the position of the temporal adverb is unambiguously inside the embedded clause. Given Cinque's 1999, 2004 hierarchy and his hypothesis that Adverb Phrases occupy specifier positions of distinct functional projections, temporal adverbs like then and tomorrow are licensed in the Specifier position of a TP projection. Hence such a projection must be present in the structure of finite control clauses in Persian, and the head of this projection must be $[+\mathrm{T}]$. This conclusion is obviously at odds with the conclusion we reached on the basis of (9), which supported the view that subjunctive control clauses are $[-\mathrm{T}]$, rather than $[+\mathrm{T}]$.

In order to solve this puzzle, we propose to replace the binary feature system used in Landau 2004, 2013 by a system that is based on feature interpretability and feature valuation. Section 4 will describe such a system in more detail and will show how Landau's generalization in (7) could be 'translated' in this system. Section 5 will then show how this new framework is able to account for the apparent conflictual results we have reached with respect to the $T$ feature of subjunctive control clauses in Persian. Finally, section 6 will discuss yet another advantage of this system: it allows us to account for the fact that subjunctive control clauses in Persian do not allow overt subjects, even if the latter are coindexed with a matrix argument.

\section{Non-binary features}

The system of features we propose to use in order to account for the Persian facts described above was initially proposed by Chomsky 2001 and then further refined by Pesetsky and Torrego 2007. In this system features fall into different types on the basis of two distinctions: the interpretable/uninterpretable distinction, and the valued/ 
unvalued distinction. The interpretable/uninterpretable distinction is semantically based: if a given feature is interpretable, it will receive an interpretation at an interface level, if not, the interfaces won't be able to interpret it (Chomsky 1995). Hence uninterpretable features must be deleted in the course of syntactic derivation. The mechanism that allows the deletion of uninterpretable features is based on an operation called Agree: an uninterpretable feature searches for a matching feature which is interpretable. Once the match is found the two features enter an Agree relation and the uninterpretable feature is checked and deleted. Apart from the interpretable uninterpretable distinction, Chomsky 2001 also introduces a distinction between valued and unvalued features. Features are thus assumed to be ordered pairs consisting of an Attribute and a value. Some features are valued lexically and others receive a value during the derivation. Chomsky 2001 ties valuation and interpretability, arguing that all and only uninterpretable features (uFs) are unvalued.

(15) A feature $\mathrm{F}$ is uninterpretable iff $\mathrm{F}$ is unvalued (Chomsky 2001)

Chomsky 2001 suggests that this biconditional reflects the fact that the mechanisms of syntax could not inspect a feature and determine whether the semantics will or will not assign an interpretation to it, but could instead inspect the feature and determine whether it is valued or not.

Given (15), deletion of uninterpretable features now depends on valuation, in the sense that only uninterpretable features that have been valued in the derivation can (and must) be deleted.

Pesetsky and Torrego 2007 propose two modifications of Chomsky 2001. One proposal is that valuation and interpretability should be treated as independent from each other. Under this assumption, the whole array of possible features includes four types of features, rather than two.

(16) - [uF:val] - an uninterpretable and valued feature

- [iF:val] - an interpretable and valued feature

- [uF: ] - an uninterpretable and unvalued feature

- [iF: ] - an interpretable and unvalued feature

A second modification proposed by Pesetsky and Torrego 2007 has to do with feature sharing. In Chomsky's 2001 framework, there is no permanent connection between a feature that gets valued in the derivation by Agree, and the feature that gave it value: once valuation takes place syntax no longer has access to the process. Pesetsky and Torrego 2007 suggest instead that valuation of a feature by matching feature creates a permanent link between the two features that is accessible to subsequent (syntactic) processes. When Agree applies between a probe feature $\mathrm{F}$ at a syntactic location $\alpha$ and a goal feature $\mathrm{F}$ at location $\beta$, the output is a single feature $\mathrm{F}$ shared by the two locations. Agreement thus results in feature sharing.

\section{The [T] feature in Pesetsky and Torrego's 2007 framework}

\subsection{Two mechanisms of achieving interpretability}

We will now show how Pesetsky and Torrego's 2007 framework is able to account for the apparent conflictual results we have reached with respect to the $\mathrm{T}$ feature of subjunctive control clauses in Persian. For Pesetsky and Torrego 2007, the Tense feature on the T head is interpretable but unvalued. On the other hand, the [Tense] feature on the verb is uninterpretable and its valuation depends on whether the verb is finite or nonfinite. More specifically, finite $v$ 's have an uninterpretable [Tense] feature which is valued, while non-finite $v$ 's have an uninterpretable $[\mathrm{T}]$ feature which is unvalued.
(17) a. T
Finite $v$
[iT: ] [uT:val]
b. $\mathrm{T} \quad$ Non-finite $v$
[iT: ] [uT:]

In order to show how the [T] feature of a subjunctive control clause in Persian is valued, it is important to bear in mind that the $\mathrm{T}$ head is not merged in the derivation bearing [Tense] features, but inherits these features from C, the phase head (Chomsky 2000, 2001, 2004, 2008). Thus, the configuration including all the relevant heads for Persian subjunctive control clauses looks like (18).

$\begin{array}{lllll}\text { (18) T } & v & {[\mathrm{C}} & \mathrm{T} & \left.\text { v }_{\text {Subjunctive }}\right] \\ \text { [iT: }] & {[\mathrm{uT:val}]} & {[\mathrm{iT}:]} & {[\mathrm{iT:}]} & {[\mathrm{uT:}]}\end{array}$

Notice that we are assuming that the embedded subjunctive $v$ bears an uninterpretable [Tense] feature which is unvalued. In this, subjunctive verbs in control clauses in Persian resemble non-finite verbs. We will see below that subjunctive verbs in control clauses differ from non finite verbs as fas as their agreement (phi) features are concerned. 
Focusing first on the embedded clause, it should be clear that the [Tense] feature on the embedded $\mathrm{T}$ head cannot get valued inside the embedded clause, since no head within the embedded clause bears a valued [T] feature. This is what prevents the embedded $\mathrm{T}$ head from licensing a temporal modifier that is independent from the temporal reference of the matrix T. Even though the [T] feature cannot be valued inside the embedded clause, Agree does take place between the [T] feature of the $\mathrm{C} / \mathrm{T}$ heads and the [T] feature of $v$, and a link is established between the [T] properties of these heads, as a consequence of feature sharing.

Focusing now on the matrix clause, the $[\mathrm{T}]$ feature on the matrix T head probes and enters an Agree relation with the valued [T] feature of the matrix $v$. The now valued [T] feature on the matrix $\mathrm{T}$ head can also value the $[\mathrm{T}]$ feature on the embedded $\mathrm{C}$ head. Once valuation happens, this value should spread to the embedded $\mathrm{T}$ and $v$ heads, given that $\mathrm{C}$ has established a link with these heads. However, the embedded $\mathrm{T}$ and $v$ heads are in different local domains (phases). The [Tense] feature on the embedded $\mathrm{T}$ and $v$ heads will thus remain unvalued in the syntax. This should normally result in ungrammaticality since the semantics interface will not be able to assign an interpretation to an unvalued feature. Notice however that even though the [Tense] feature on embedded $\mathrm{T}$ and $v$ is unvalued, both $\mathrm{T}$ and $v$ bear an interpretable [Tense] feature. Moreover, this feature is linked to the matrix $\mathrm{T} / v$ by virtue of the feature sharing mechanism. We propose that the interface interprets this as an instruction to assign the embedded $\mathrm{T}$ the same index as the matrix $\mathrm{T}$, with which $\mathrm{T}$ is linked by feature sharing. Thus, there are two mechanisms by which $\mathrm{T}$ can obtain an interpretation at LF: one is feature valuation, a process that depends on Agree and that takes place in the syntactic component, and the other one is assigning interpretable $[\mathrm{T}]$ the same index as the other shared instances of this feature. In particular, this means assigning to the embedded $\mathrm{T} / v$ the same index as the matrix $\mathrm{T} / v$. This would be the correlate of the notion of temporal anaphor ${ }^{3}$.

We could thus equate Landau's 2013 [-T] feature with a $[\mathrm{T}]$ feature that fails to get valued in the syntax. On the other hand, what we called a $[+\mathrm{T}]$ feature in Landau's 2013 system translates in this framework as a [T] feature that is assigned an interpretation. Both mechanisms described above are suitable ones for $\mathrm{T}$ to obtain an interpretation, and in the case of subjunctive clauses embedded under obligatory control verbs in Persian, the relevant mechanism is an interface one that consists in assigning $T$ the index of the other items with

\footnotetext{
3 This proposal could potentially be extended to binding in general, but we have not pursued this and we leave this to future research.
}

which $\mathrm{T}$ is linked by feature sharing. The embedded $\mathrm{T}$ is able to licence a temporal modifier by virtue of having an interpretive index, but given that this index is identical to the index that the matrix $\mathrm{T}$ bears, the modifier is licensed only on condition it is compatible with the temporal reference of the matrix $\mathrm{T}$.

\subsection{The referential index of PRO}

The same system (i.e. Pesetsky and Torrego 2007) could account for the interpretation of PRO in subjunctive control clauses in Persian. Recall that one of the conditions for obligatory control to obtain is that PRO be coindexed with a codependent of the clause that contains it (condition (a) in the OC signature in (4). However, in order to establish how PRO gets its referential index, a prior question has to be addressed, namely, what is a referential index; what does a referential index mean in terms of features? We propose that a referential index on a nominal indicates the presence of two features on that nominal: an [R] (for referential) feature, and [phi] features, both of which are commonly assumed to characterize nominals. We also propose that the [R] feature and [phi] features of PRO are both interpretable but unvalued. This assumption will set big PRO apart from little pro, which also has [phi] features, but in the case of little pro these features are valued (Holmberg 2005, 2010). Unlike little pro, big PRO will come to bear a referential index only if its [R] feature and its [phi] features can get interpreted at LF. This can be achieved in two ways: either these features get valued in the syntax by agreement with another element that bears matching (valued) features, or else by feature sharing with an item that bears matching (valued) features. The relevant item that bears matching features with PRO is the T head. Moreover, the phi features are not intrinsically present on the $\mathrm{T}$ head, but are inherited from the $\mathrm{C}$ head (Chomsky 2000, 2001, 2004, 2008). We will extend the same assumption to the $[\mathrm{R}]$ feature. More specifically, we will assume that $\mathrm{C}$ bears [phi] features and an [R] feature, both of which are uninterpretable and unvalued, and that $\mathrm{C}$ transmits these features to the T head.

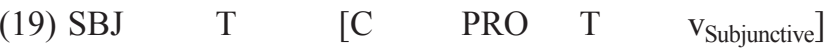 [iphi:val] [uphi: ] [uphi: ] [iphi: ] [uphi: ] [iR:val] [uR: ] [uR: ] [iR: ] [uR: ]}

Notice that even though the embedded $\mathrm{C} / \mathrm{T}$ bear matching features, $\mathrm{C} / \mathrm{T}$ cannot value the [phi] and $[\mathrm{R}]$ features on PRO, since these features are unvalued on $\mathrm{C} / \mathrm{T}$. However, the embedded $\mathrm{C}$ enters an Agree relation with the matrix $\mathrm{T}$, which in turn agrees with the matrix 
subject (whose $\mathrm{R}$ and phi features are valued). Even though the values of the $[R]$ and [phi] features on $C$ cannot be transmitted to the embedded T and PRO (the two are in a different phase, which has been sent to the interfaces by the time the phi features on $\mathrm{C}$ get valued), it is still the case that $\mathrm{C}, \mathrm{T}$ and $\mathrm{PRO}$ are linked by virtue of feature sharing. Thus, at the interface level, PRO, and derivatively the embedded $\mathrm{T}$, will be assigned an interpretive index that is identical with the index of the shared instances of this feature. In particular, PRO will come to bear the same index as the matrix subject.

At this point, it seems redundant to posit both [phi] features and the [R] feature in order to explain the mechanism that creates the anaphoric link between the embedded $\mathrm{T}$ and the matrix T. Either the [phi] features or the [R] feature would be enough to account for this anaphoric link. Since [phi] features have an overt morphophonological correlate on both nouns and verbs, it seems natural to assume that the superfluous feature in our case is the $[\mathrm{R}]$ feature, rather than the [phi] features. However, there is evidence that we actually need both [phi] features and the $[R]$ feature in order to account for the Persian facts. The evidence is related to the availability of overt subjects in subjunctive control clauses.

According to Landau 2013, overt pronominal subjects in finite control clauses are expected to be grammatical, on condition their reference is shared or controlled by a matrix NP. This restriction also applies to Persiansubjunctive control clauses do not allow overt subjects that are disjoint in reference from the matrix subject.

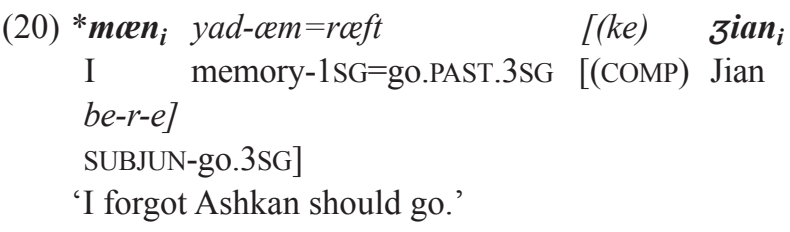

In order to account for this restriction, we could say that the embedded $\mathrm{T}$ ends up with conflictual [phi] features. On the one hand, the [phi] features on embedded $\mathrm{T}$ are valued by the [phi] features of the overt embedded subject. On the other hand, embedded T is coindexed with matrix $\mathrm{T}$, (as explained in section 5.1), which means that all the features of the embedded $\mathrm{T}$ must be linked to the matrix T, including the [phi] features. Having the [phi] features on the embedded $\mathrm{T}$ valued independently, by an overt subject that bears different [phi] features would be in conflict with the index shared between the embedded $\mathrm{T}$ and the matrix $\mathrm{T}$.

This kind of account (which relies exclusively on the mechanism of valuing the phi features on PRO) would explain why subjunctive control clauses can't have overt subjects whose phi features are different from the [phi] features of the matrix subject/T, but crucially, it could not explain why subjunctive control clauses also disallow overt subjects whose [phi] features are identical with the [phi] features of the matrix subject/T.

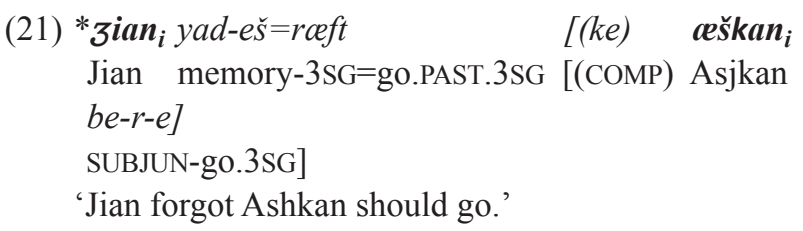

In (21) both Zian - the subject of the matrix clause, and ceškan - the subject of the embedded clause, have the same [phi] features: 3rd person singular, masculine, and yet the string is ungrammatical.

Using an [R] feature on top of the [phi] features could account for the fact that what is important in these contexts is that the two subjects bear the same referential index, which is related to but not reducible to the [phi] features that the two subjects bear. Thus, in (21), the [R] feature of the embedded subject will have a different value than the [R] feature on the matrix subject. Hence the [R] feature on the embedded $\mathrm{T}$ will also be valued differently than the $[R]$ feature on the matrix $T$. This will create a clash between the disjoint index on the $[\mathrm{R}]$ feature on the embedded $\mathrm{T}$ and the anaphoric index on the [phi] and [T] features on the embedded $\mathrm{T}$ and ungrammaticality will result.

The [R] feature we propose is not something new. Landau's 2004, 2013 account for example also makes use of an $[R]$ feature and assumes that nominals capable of independent reference are $[+R]$, whereas anaphoric nominals are [-R]. Landau is in turn following Reinhart and Reuland 1993 and Reuland and Reinhart 1995, in proposing this feature.

In Landau's 2004, 2013 account, whether a particular nominal bears $[+\mathrm{R}]$ or $[-\mathrm{R}]$ depends on clausal features (i.e. features of functional categories like C, Infl, etc.) and can be 'calculated' on the basis of the following universal implicational relation between clausal features and nominal features:

(22) R-assignment Rule. (Landau 2004)

$$
\begin{aligned}
& \text { For } \mathrm{X}^{0}[\alpha \mathrm{T}, \beta \text { Agr }] \in\left\{\mathrm{I}^{0}, \mathrm{C}^{0}, \ldots\right\}: \\
& \varnothing \rightarrow[+\mathrm{R}] / \mathrm{X}^{0}[], \text { if } \alpha=\beta={ }^{\circ}+ \\
& \varnothing \rightarrow[-\mathrm{R}] / \text { elsewhere }
\end{aligned}
$$

The R-assignment rule states that whenever or are specified for $[+\mathrm{T},+\mathrm{Agr}]$, they automatically come to bear $[+\mathrm{R}]$, and that any other feature constitution $-[+\mathrm{T},-\mathrm{Agr}]$, 
$[-\mathrm{T},+\mathrm{Agr}]$ or $[-\mathrm{T},-\mathrm{Agr}]-$ is associated with [-R]. While in Landau's account the R-assignment rule is a stipulation, in our analysis, the $\mathrm{R}$ feature is a regular feature that is subject to the same rules as any other feature: it can be interpretable or uninterpretable, valued or unvalued, and its checking and valuation proceeds according to a mechanism based on Agree, just like any other feature.

\subsection{Bonus}

An additional benefit of this using a feature system based on interpretability and valuation distinctions is that this system can also account for a surprising further restriction on subjunctive control clauses in Persian: overt embedded subjects are always ungrammatical in Persian, whether they are disjoint in reference from the matrix subject or coreferential with the latter.

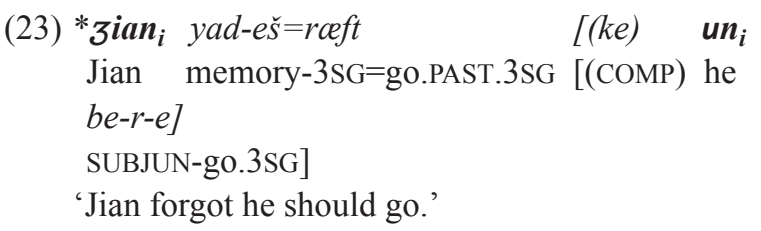

Notice that in (23) the embedded subject is coreferential with the matrix subject, which means that the two have the same value for both their [phi] features and their $[\mathrm{R}]$ feature.

This is surprising under Landau's 2004, 2013 analysis, where overt embedded subjects which are coreferential with the matrix subject are assumed to be grammatical, as illustrated in (24).

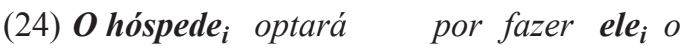
The guest will.choose up to.do he the pequeno-almoço todos os dias breakfast every the days 'The guest will choose to prepare his breakfast himself every day.' (Landau 2013, ex.71.b)

In fact, this restriction is also surprising given our analysis so far. Given that the two subjects bear the sasme referential index in ), it must be that their phi and $\mathrm{R}$ features are interpreted in the same way at LF, which does not in any way conflict with the links created by feature sharing. It is therefore not clear why (23) is ungrammatical.

We propose that the general framework that we have adopted can in fact account for the restriction in (23), but that an additional feature should be taken into account, namely [Case]. We will adopt Pesetsky and Torrego 2001's analysis of nominative case as an unvalued [uT] feature on NP/DP subjects. We are also assuming that structural [Case] is a syntactic feature that must be checked and valued in the syntax. The [uT] feature of the embedded subject cannot be checked and valued inside the embedded clause before spell out since no head within the embedded clause bears a valued [T] feature. Even though the embedded [T] feature does eventually receive an interpretation, via the mechanism of feature sharing, the coindexation mechanism is post-syntactic, as described above, in section 5.1. Since [Case] is a syntactic feature that has to be valued in the syntax and since syntactic valuation of the $[\mathrm{uT}]$ feature on the subject is not an option, the derivation fails and ungrammaticality results.

\subsection{Subjunctives vs infinitives}

One remaining question concerns the difference between finite and non-finite control, in our specific case the difference between subjunctive clauses embedded under $\mathrm{OC}$ verbs and infinitive clauses embedded under OC verbs. Given that the embedded subjunctive $\mathrm{C} / \mathrm{T}$ have an unvalued [iT: ] feature, just as the infinitive $\mathrm{C} / \mathrm{T}$, the difference between the two cannot be about the [T] feature. Intuitively, subjunctive verbs differ from infinitive ones with respect to their agreement features: subjunctive verbs are overtly inflected for agreement, whereas infinitive verbs are not. We could therefore say that an infinitive $\mathrm{T}$ bears no [phi] features, and we could extend the same assumption to the $[R]$ feature.

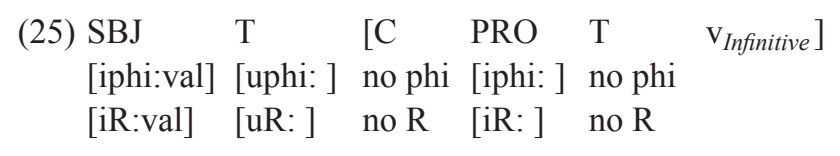

However, it is not clear how PRO gets a referential index in infinitival control clauses under these assumptions. Clearly, the valuation of PRO's [phi] and [R] features cannot take place in the syntax, since there is no head in the embedded clause that bear relevant valued features. The alternative mechanism-via feature sharing, could in principle be available, given appropriate features on the embedded $\mathrm{C}$. The literature is divided with respect to the $\mathrm{C}$ head in infinitival clauses. According to Boskovic 1997, Hornstein and Lightfoot 1987, Koster 1984, Bouchard 1984, etc. control infinitival complements are IPs/TPs, rather than CPs. In other words, infinitive clauses selected by control verbs have no $\mathrm{C}$ at all.

$\begin{array}{lllll}\text { (26) SBJ } & \text { T } & \text { PRO } & \mathrm{T} & \mathrm{V}_{\text {Infinitive }} \\ \text { [iphi:val] } & \text { [uphi: ] } & \text { [iphi: ] no phi } & \\ \text { [iR:val] } & \text { [uR: ] } & \text { [iR: ] } & \text { no R }\end{array}$


In this case, the referential index of PRO will be assigned on the basis of syntactic valuation, since its [phi] and [R] features will be able to be valued by the matrix $\mathrm{T}$, which in turn agrees with the matrix subject. Syntactic valuation of PRO's features is possible in this case since with the CP layer absent, there is no phasal boundary between $\mathrm{PRO}$ and its probe, the matrix $\mathrm{T}$.

Not all authors agree however that infinitival control clauses lack a CP layer. In Pesetsky's 1992 view, for example, all clausal complements, including infinitival ones, are CPs. Under this view, the $\mathrm{C}$ head of infinitival control clauses is assumed to be defective in that it lacks [phi] features, as represented in (25) (Landau 2004, 2013). The challenge in this case is that PRO cannot value its [phi] and [R] features in the syntax, and the feature sharing mechanism is not helpful either, given that PRO does not share its features with the matrix $\mathrm{T}$ (the matrix T cannot 'reach' PRO in order to establish an Agree relation with it, since PRO is in a different phase/ domain than matrix T). We propose that PRO does in fact get its referential index via feature sharing but that the relevant feature is not [phi] of [R], but [Case]. We follow Chomsky and Lasnik 1995, Martin 2001, Sigurdsson 1991, Baltin and Barett 2002, among others, in assuming that PRO bears a [Case] feature that needs to be checked against an agreeing feature on $\mathrm{T}$. This could be a special null Case, as proposed by Chomsky and Lasnik 1995 and Martin 2001, or it could be nominative Case, as proposed by Sigurdsson 1991, and Baltin and Barett 2002. In either situation, this feature will provide the missing link that will allow PRO to share a feature with T. Given that T shares features with the matrix $T$ and derivatively with the matrix subject, PRO will ultimately share features with the matrix subject.

\section{Conclusions}

In this paper we focused on finite control in Persian, a language in which clauses embedded under obligatory control verbs can be inflected for the subjunctive. We showed that the ambivalent nature of $T$ in these contexts can be accounted for in a system which uses an interpretable/uninterpretable distinction, as well as a valued/unvalued distinction, and in which valuation and interpretability are independent from each other (Pesetsky and Torrego 2007). We proposed that there are two mechanisms by which $\mathrm{T}$ can obtain an interpretation at LF: one is feature valuation, a process that depends on Agree and that takes place in the syntactic component, and the other one is index sharing-assigning interpretable $[\mathrm{T}]$ the same index as the other shared instances of this feature. In the particular case of Persian finite control, the [tense] feature of the embedded $\mathrm{T}$ head fails to get valued in the syntax inside the embedded clause, but it is still assigned an interpretation post syntactically, at the LF interface, by virtue of the feature sharing mechanism. The same mechanism was shown to apply to deriving the referential index of PRO - the null subject of the finite control clause in Persian. We proposed that the referential index of a nominal depends on morpho-syntactic features like [phi] features and the [R] feature. Just as in the case of the $[\mathrm{T}]$ feature, there are two mechanisms via which the $[R]$ feature and the [phi] features can receive an interpretation at LF: either these features get valued in the syntax by agreement with another element that bears matching (valued) features, or else by feature sharing.

\section{References}

BALTIN, Mark; BARETT, Leslie. The Null Content of Null Case. Ms. NY University, 2002.

BOŠKOVIĆ, Željko. The Syntax of Non-finite Complementation: an Economy Approach. MA: MIT Press, 1997.

BOUCHARD, Denis. On the Content of Empty Categories. Dordrecht: Foris Publications, 1984.

CHOMSKY, Noam. The Minimalist Program, Cambridge, MA: MIT Press, 1995.

CHOMSKY, Noam. Minimalist inquiries. In: MARTIN, Roger; MICHAELS, David; URIAGEREKA, Juan (eds.). Step by step. Cambridge: MIT Press, 2000. p. 89-155.

CHOMSKY, Noam. Derivation by phase. In: KENSTOWITCZ, Michael (ed.). Ken Hale: A life in language. MIT Press, 2001. p. $1-52$.

CHOMSKY, Noam. Beyond Explanatory Adequacy. Structures and Beyond. In: BELETTI, Adriana (ed.). The Cartography of Syntactic Structures, 3. Oxford: Oxford University Press, 2004. p. 104-131.

CHOMSKY, Noam. On phases. In: FREIDIN, Robert; OTERO, P. Carlos; ZUBIZARETA, Maria Luisa (eds.). Foundational Issues in Linguistic Theory. Cambridge, Mass: MIT Press, 2008. p. 133-167.

CHOMSKY, Noam; Howard LASNIK. The Theory of Principles and Parameters. In: CHOMSKY, Noam (ed.). The Minimalist Program. Cambridge, Mass: MIT Press, 1995. p. 13-127.

CINQUE, Guglielmo. Adverbs and functional heads: A crosslinguistics perspective. Oxford: Oxford University Press, 1999.

CINQUE, Guglielmo. Issues in adverbial syntax. Lingua, 114. p. 683-710. 2004.

DARZI, Ali. On the vP analysis of Persian finite control constructions. Linguistic Inquiry, v. 39, n. 1, p. 103-116, 2008.

GOMESHI, Jila. Control and thematic agreement. The Canadian Journal of Linguistics, v. 46, n. 1-2, p. 9-40, 2001.

HASHEMIPOUR, Margaret Marie. Pronominalization and control in modern Persian. Ph.D. thesis. University of California, San Diego, 1989.

HOLMBERG, Anders. Is There a Little Pro? Evidence from Finnish. Linguistic Inquiry, v. 36, n. 4, p. 533-564, 2005. 
HOLMBERG, Anders. Null subject parameters. In: BIBERAUER, Teresa; HOLMBERG, Anders; ROBERTS, Ian (eds.). Parametric Variation. Null subjects in minimalist theory. Cambridge: Cambrigde University Press, 2010. p. 88-124.

HORNSTEIN, Norbert; LIGHTFOOT, David. Predication and PRO. Language, v. 63, p. 23-52, 1987.

ILKHANIPOUR, Negin. On the CP analysis of Persian finite control constructions. Linguistic Inquiry, v. 45, n. 2, p. 323-331, 2014.

KARIMI, Simin. Raising and control in Persian. In: KARIMI, Simin; SAMIIAN, Vida; STILO, Don (eds.). Aspects of Iranian linguistics. Cambridge Scholars Publishers. 2008. p. 177-208.

KOSTER, Jan. On Binding ad Control. Linguistic Inquiry, v. 15 , p. 417-459. 1984.

LANDAU, Idan. The scale of finiteness and the calculus of control. Natural Language and Linguistic Theory, v. 22, n. 4, p. 811-877, 2004.

LANDAU, Idan. Control in generative grammar: A research companion. Cambridge University Press, 2013.

MARTIN, Roger. Null Case and the Distribution of PRO. Linguistic Inquiry, v. 32, n. 1, p. 141-166, 2001.

PESETSKY, David. Zero Sntax II: an essay on Infinitives. Ms. MIT, 1992.

PESETSKY, David; TORREGO, Esther. T-to-C movement: Causes and consequences. In: KENSTOWICZ, Michael (ed.).
Ken Hale: A life in language. Cambridge, Mass: MIT Press, 2001. p. 355-426.

PESETSKY, David; TORREGO, Esther. The syntax of valuation and the interpretability of features. In: KARIMI, Simin; SAMIIAN, Vida; WILKINS, Wendy K. (eds.). Phrasal and Clausal Architecture: Syntactic derivation and interpretation. John Benjamins, 2007. p. 262-294.

REINHART, Tanya; REULAND, Eric. Reflexivity. Linguistic Inquiry, v. 24, p. 657-720, 1993.

REULAND, Eric; REINHART, Tanya. Pronouns, Anaphors and Case. In: HAIDER, Hubert; OLSEN, Susan; VIKNER, Sten (eds.). Studies in Comparative Germanic Syntax. Kluwer Academic Publishers, Dordrecht, 1995. p. 241-268.

RICHARDSON, Ivanna. Obligatory Control in Persian. MA thesis. Concordia University, 2016.

SIGURDSSON, Halldor A. Icelandic Case-Marked PRO and the Licensing of Lexical Arguments. Natural Language and Linguistic Theory, 9, p. 327-363, 1991.

TALEGHANI, Azita. The Interaction of Modality, Aspect and Negation in Persian. Ph.D. thesis, University of Arizona, 2006.

Recebido: 30 de janeiro de 2016

Aprovado: 02 de junho de 2016

Contato: dana.isac@concordia.ca ivannafrancisswann@gmail.com 